\title{
Trade Flows and IPR Protection: A Dynamic Analysis of the Experience of ASEAN-6 Countries
}

\author{
YOON HEO* AND NGUYEN KHANH DOANH**
}

\begin{abstract}
This paper examines the impacts of intellectual property rights (IPR) protection in foreign markets on ASEAN countries' exports for the period 2005-2010 using a dynamic panel data model, which allows us to account for persistence effects. In order to solve the inconsistency of OLS in a dynamic modelling, we opt for the system GMM estimator because it helps researchers overcome the problems of serial correlation, heteroskedasticity, and endogeneity for some explanatory variables. Our results are robust and summarized as follows. First, reinforced IPR protection in foreign countries has a positive effect on ASEAN's exports, indicating the dominance of market expansion effects. Second, regardless of the level of economic development in importing countries, stronger IPR protection induces ASEAN's exports to foreign countries. Third, the trade impacts of IPR protection are strongest in high-income trading partners, followed by medium-income, and finally, low-income partner countries. Fourth, at the sectoral level, the effect of IPR protection is found to be the strongest for capital-intensive exports to highly developed countries and the weakest for capital-intensive exports to less developed countries. Thus, it is likely that ASEAN's exports will increase if appropriate measures are taken to strengthen IPR protection in foreign countries.
\end{abstract}

Keywords: Intellectual Property Rights, Imitative Ability, System GMM Estimator, ASEAN, Gravity Model

* Professor, Sogang University, Seoul, Korea; E-mail: hury@sogang.ac.kr

** Associate Professor, Thai Nguyen University of Economics and Business Administration, Vietnam; E-mail: nkdoanh@yahoo.com

DOI: 10.16934/isr.16.1.201506.59 


\section{INTRODUCTION}

The linkage between intellectual property rights (IPR) protection and international trade flows has remained ambiguous, thereby serving as a potential source of controversy in academia. Many researchers have attempted to theorize how IPR protection affects international trade flows. However, they have not been able to predict the direction of the impacts, because the reinforcement of IPR protection can have two countervailing effects on international trade flows: market power and market expansion (Ethier and Markusen 1996; Maskus 2000; Smith 2002). A market power effect occurs when stronger IPR protection in the importing countries induces the exporting countries to reduce their exports to the importing countries. There are two possible explanations for this. The first is that the strengthening of IPR protection in the importing countries grants monopoly power to the exporting countries. Thus, the exporting countries might try to profit by reducing their output and charging a monopoly price. The second explanation is that stronger IPR protection in the importing country increases the cost of imitation incurred by local firms. Accordingly, firms in the exporting country are encouraged to serve foreign markets through foreign direct investment (FDI) or licensing rather than exports (Ferrantino 1993; Lee and Mansfield 1996). A market expansion effect occurs when increased IPR protection in the importing countries encourages exporting countries to export more to importing countries; stronger IPR protection in the importing countries hinders local firms in the importing countries from imitating foreign goods. The resulting reduction in the production of imitated foreign goods in the importing countries increases net demand for the protected foreign goods. This encourages foreign firms with superior technologies to increase exports to those markets (Maskus 1998; Seyoum 1996).

In line with theoretical ambiguity, many empirical studies have attempted to test the dominance of market power and/or market expansion effects (Al-Mawali 2005; Fink and Primo-Braga 2005; Heo and Doanh 2012; Wen-Hsien and Lin 2005; Maskus and Penubarti 1995; Rafiquzzaman 2002; Smith 1999, 2002). Their results show that the impact of stronger IPR protection on international trade flows is case-specific.

A more sophisticated theory focuses on the threat of imitation in the importing countries. This threat is determined by the interaction between imitative abilities and patent laws. It is assumed to be weaker in countries with weak imitative abilities and strong patent laws. Alternatively, it is supposed to be stronger in countries having strong imitative abilities and weak patent laws. The theory predicts that IPR causes a market expansion effect and a market power effect for an importing country that poses a strong threat of imitation and a weak threat of imitation, respectively. In addition, the importance of these effects is likely to depend on product types and market characteristics. For example, some commodities are 
easier to imitate than others, and some have closer substitutes than others. The impacts of IPR protection also depend on the exporters. If the exporter is not an innovator, then IPR protection is not that important to international trade flows.

In summary, the theoretical foundation and empirical evidence on the subject reveal the following. First, the linkage between IPR protection and trade flows depends on the relative strength of market power effects or market expansion effects. Second, market expansion effects tend to dominate when importing countries pose a strong threat of imitation. Third, the impact of IPR protection on international trade flows also depends on product characteristics because some products are more difficult to imitate than others. The former case will potentially lead to market power effects, while the later will probably result in market expansion effects.

Using data from ASEAN countries, the objective of this study is to analyze the trade impacts of IPR protection by using a system generalized method of moments (GMM) estimator. To accomplish this objective, this research is guided by the following three questions:

- What is the impact of reinforced IPR protection in importing countries on ASEAN's exports?

- How does the impact of IPR enforcement vary among different importing countries grouped by their levels of economic development?

- Do different commodity groups exhibit divergent patterns in their trade impacts of IPR protection depending on the level of the importing countries' economic development?

This paper is unique in three ways. First, we apply dynamic modeling, which allows us to take into account autocorrelation in the residuals and helps mitigate the amount of potential spurious regression. In order to solve the inconsistency of OLS in a dynamic modelling, we opt for the system GMM estimator because it helps researchers overcome the problems of serial correlation, heteroskedasticity, and endogeneity for some explanatory variables. Second, the study bases its analysis on the most recent panel data, which allow patent regimes to change over time. Finally, to measure the status of an IPR regime, we use the IPR index developed by the Economic Freedom of the World project, which enables us to utilize both cross-sectional as well as time-series IPR data.

\section{MODEL}

\section{Model Specification}

In order to estimate the impacts of IPR protection on international trade flows, we adopt a gravity model with some variations. The gravity model has been com- 
monly applied to explain international trade flows between countries. Specifically, the model relates a trade flow from country $i$ to country $j$ to the supply condition in country $i$, the demand condition in country $j$, and the forces that either stimulate or resist the movement of trade flows. The regression equation in log-linear form is as follows:

$$
\begin{aligned}
\log Y_{i j t}= & \alpha+\beta_{1} \log X_{i t}+\beta_{2} \log X_{j t}+\beta_{3} \log D_{i j}+\beta_{4} Z_{i j}+\beta_{5} I P R_{j t} \times L D_{j t} \\
& +\beta_{6} I P R_{j t} \times M D_{j t}+\beta_{7} I P R_{j t} \times H D_{j t}+e_{i j t}
\end{aligned}
$$

Where: $\mathrm{Y}_{\mathrm{ijt}}$ is export from country $i$ (ASEAN-6 countries) to country $j$ (ASEAN-6 countries' trading partners). $X_{\text {it }}$ is a list of time-varying exporter variables, while $\mathrm{X}_{\mathrm{jt}}$ is a list of time-varying importer variables. These variables include GDP, population, area and openness. $\mathrm{D}_{\mathrm{ij}}$ is geographical distance between $i$ and $j . \mathrm{Z}_{\mathrm{ij}}$ is a list of dummy time-invariant variables. These variables include common language, colonial relationship and landlocked countries.

The model presented in Eq. (1) is static in nature. However, in reality, countries that trade with each other at the time $t$ have the tendency to maintain their trading relations at the time $t+1$. The reason is that the exporting countries have to make initial investment in setting up the network in their trading partners. Therefore, the static specification in equation 1 can be enhanced by adding lagged dependent variable, which allows feedback from past shocks to current values of the dependent variable. The Eq. (1) can be expressed in the following dynamic fashion as follows:

$$
\begin{aligned}
\log Y_{i j t}= & \alpha+\beta_{1} \log Y_{i j, t-1}+\beta_{2} \log X_{i t}+\beta_{3} \log X_{j t}+\beta_{4} \log D_{i j}+\beta_{5} Z_{i j}+\beta_{6} I P R_{j t} \times L D_{j t} \\
& +\beta_{7} I P R_{j t} \times M D_{j t}+\beta_{8} I P R_{j t} \times H D_{j t}+e_{i j t}
\end{aligned}
$$

The descriptions and measurements of the variables used in Eq. (1) are as follows:

- Gross Domestic Product $\left(G_{D D}\right.$ it $\left._{\text {and }} G_{D D} \boldsymbol{P}_{\mathrm{j} t}\right)$ : The inclusion of the supply factor of the exporting country and the demand factor of the importing country is justified on the ground that a higher GDP of the exporting country expands domestic production for exports, while a higher GDP of the importing country suggests higher demand for imports. Therefore, it is expected that trade increases with country size (Frankel 1993; Jafari et al. 2011). In other words, the gravity theory predicts that the GDP parameters will be positive. In this paper, GDP $i t$ is the GDP of the exporting country $i$ at time $t$, while $\mathrm{GDP}_{j t}$ is the GDP of the importing country $j$ at time $t$.

- Population (POP it $\left._{\text {and }} \boldsymbol{P O P}_{\mathrm{j} t}\right)$ : The theoretical justification for population variables is somewhat imprecise. On the one hand, a large population could promote a 
division of labor and allow more industries to reach efficient economies of scale. Thus, opportunities for trade with foreign partners in a wide variety of goods will increase, suggesting a positive impact of population on bilateral trade (Oguledo and MacPhee 1994). On the other hand, populous countries are assumed to be larger in area, and thus, they are expected to be endowed with a greater quantity and variety of natural resources. The larger absorption effect of this domestic market causes less reliance on international trade transactions, indicating a negative impact of population on bilateral trade (Endoh 2000; Martinez-Zarzoso and Nowak-Lehmann 2003). Therefore, the coefficients of population could be positive or negative, depending on whether the absorption effect or economies of scale effect is dominant. In this paper, $\mathrm{POP}_{i t}$ is the population of country $i$ at time $t$, and $\mathrm{POP}_{j t}$, of country $j$ at time $t$.

- Distance (DIST $\boldsymbol{T}_{\mathrm{ij}}$ ): Geographical distance between trading partners is used as a representative proxy for the cost of international trade, which includes transport cost, cost of time, and access to relevant market information. All these factors reflect the cost of international transactions of goods and services and are expected to affect trade negatively (Al-Mawali 2005; Sohn 2005). Therefore, we expect the sign of the coefficient of $\operatorname{DIST}_{i j}$ to be negative. In this paper, DIST $i j$ is geographical distance, measured as the crow flies, between the capital cities of countries $i$ and $j$.

- Land areas (Area $a_{\mathrm{i}}$ and Area $_{\mathrm{j}}$ ): Factor endowments are assumed to be important determinants of a country's trade. It is thought that larger countries are more diverse and potentially richer in natural resources. This might cause less reliance, and thereby, a negative effect on international trade. In contrast, it is also argued that larger countries probably have more natural resources and greater exporting capacity. This indicates a positive effect on international trade. Therefore, the coefficients of land areas could be negative or positive. In this study, the variables Area $a_{i}$ and Area $a_{j}$ are the land areas of countries $i$ and $j$ measured in $\mathrm{km}^{2}$, respectively.

- Openness to trade (Openness ${ }_{i t}$ and Openness $\mathrm{j}_{\mathrm{j} t}$ ): Following Smith (2001), we incorporate openness variables into the gravity equation, because countries with a higher level of openness tend to trade more. Therefore, we expect that the coefficient of openness is positive (Smith 2001, 2002). In this paper, Openness $i t$ is the openness index of country $i$ at time $t$, measured as the dollar value of exports as a percentage of country $i$ 's GDP, while Openness $j t$ is the openness index of country $j$ at time $t$, measured as the dollar value of exports as a percentage of country $j$ 's GDP.

- Language and colony (Language $e_{\mathrm{ij}}$ and Colony $\mathrm{ij}_{\mathrm{ij}}$ ): Since linguistic affinity and being an ex-colony tend to reduce cultural distance, and therefore to encourage bilateral trade, it is expected that the coefficients of these three dummy variables are positive (Endoh 1999; Martinez-Zarzoso 2003; Péridy 2005). In this 
paper, Language $i j$ stands for common language that equals 1 if countries $i$ and $j$ speak the same language and zero otherwise. Colony ${ }_{i j}$ is also a dummy variable that equals 1 if country $i$ was colonized by country $j$ or vice versa and zero otherwise.

- Landlock (Landlock $\boldsymbol{k}_{\mathrm{j}}$ ): The inclusion of the variable Landlock $_{j}$ is justified on the ground that being landlocked is generally considered to reduce international trade. The reason is that the number of border-crossings, which implies a transport cost burden, can explain a major part of the extra cost of overland transport over that of maritime transport (Raballand 2003). Therefore, we expect that the coefficient of Landlock ${ }_{j}$ is negative. In this paper, Landlock ${ }_{j}$ is a dummy variable that equals 1 if country $j$ is landlocked and zero otherwise.

- Intellectual property right protection $\left(I P R_{\mathrm{j}}\right)$ : To capture the impact of IPR protection on international trade flows, we use the IPR index developed by the Economic Freedom of the World project. In line with the existing literature, IPR has an indeterminate impact on trade flows due to market power and market expansion effects. Therefore, the sign of the coefficient of the IPR index could either be positive (reflecting a dominant market expansion effect) or negative (reflecting a dominant market power effect). In this paper, IPR ${ }_{j t}$ is the IPR index of country $j$ at time $t$.

- Economic development level (HD, MD, and LD): In order to construct the development dummy variables, we classify the importing countries in our sample into three groups by their levels of economic development: high income $\left(\mathrm{HD}_{j t}\right)$, middle income $\left(\mathrm{MD}_{j t}\right)$, and low income $\left(\mathrm{LD}_{j t}\right)$. Our classifications are based on the World Bank's categorization. It is possible that the trade effect of IPR protection may differ by industry and levels of economic development of the importing countries (Maskus and Penubarti 1995; Smith 1999). We let the development dummy variables interact with IPR. The estimates of interaction variables illustrate the sensitivity of ASEAN's exports to the strength of national IPR protection in countries grouped by level of development. As demonstrated theoretically, while it is known that stronger IPR protection can simultaneously increase trade through market expansion effects and decrease trade through market power effects, the direction of the impact of the interaction variables remains uncertain. A positive value indicates that within a given level of development, stronger IPR protection increases ASEAN's exports to these countries through the market expansion effect. In contrast, a negative value indicates that within a given level of development, strong IPR protection tends to reduce ASEAN's exports to these countries via the market power effect.

\section{Method of Estimation and Data}

The application of dynamic panel data model as presented in Eq. (2) raises 
econometric concerns. Specifically, the lagged dependent variable of the equation leads to correlation between the lagged dependent variable and the error term that makes the OLS estimator biased and inconsistent. In addition, GDP it and Openness $\mathrm{it}_{\mathrm{it}}$ are assumed to be endogenous because causality may run in both direc-tions. Furthermore, the panel dataset has a short time dimension and a larger coun-trypair dimension. For these reasons, we opt for the system GMM estimator, which allows us to overcome the problems of serial correlation, heteroskedasticity, and endogeneity for some explanatory variables. The estimator is a system con-sisting of both first-differenced and levels equations. To estimate the equation, we apply the Blundell and Bond methodology to small-sample correction (Blundell and Bond 1998). The GMM system is consistent if there is no second-order serial correlation in the residuals.

As the data needed for constructing the panel dataset are not available for some ASEAN member countries, we focus on ASEAN-6 because these countries are ASEAN's major trading partners. They include Indonesia, Malaysia, Philippines, Singapore, Thailand, and Vietnam. Our sample includes 106 countries (6 ASEAN member countries plus 100 non-ASEAN importing countries) for the period 2005-2010, leading to 600 country pairs and 3600 observations. The data on ASEAN countries' exports (measured in million USD) are sourced from UN Comtrade and the IMF Direction of Trade Statistics. GDP data (in million USD) are extracted from the IMF World Economic Outlook Database. Data on population (in million) are obtained from the IMF World Economic Outlook Database and Economist Intelligence Unit. Distance data (in kilometers) are collected from Indo.com (http://www.indo.com/distance/). Data for the landlock variable are sourced from the World Map. Classification of economies according to the level of income is done using the World Bank's Country Classifications. Finally, to capture the effect of IPR on bilateral trade flows, we use the IPR index from the Economic Freedom of the World project.

\section{ESTIMATED RESULTS}

\section{Overview of ASEAN's Exports}

ASEAN's international trade has grown consistently over the past two decades. The USD value of exports of goods and services increased from 130.85 billion USD in 1990 to 419.54 billion USD in 2000 and 1,116.85 billion USD in 2011. Table 1 reports ASEAN's composition of exports at SITC 1-digit levels.

As shown in Table 1, the commodity composition of exports has changed over time. While manufactured products dominate ASEAN's exports, the exports of primary products have grown only marginally. Among ASEAN's exports, the share of manufactured goods and miscellaneous manufactures in total exports has de- 
TABLE 1. ASEAN's COMMODITY COMPOSITION OF EXPORTS

\begin{tabular}{lcccccc}
\hline \multicolumn{1}{c}{ Product Description } & $\mathbf{1 9 9 0}$ & $\mathbf{1 9 9 5}$ & $\mathbf{2 0 0 0}$ & $\mathbf{2 0 0 5}$ & $\mathbf{2 0 1 0}$ & $\mathbf{2 0 1 1}$ \\
\hline Primary products & $\mathbf{3 9 . 0 5}$ & $\mathbf{2 2 . 7 1}$ & $\mathbf{1 9 . 7 2}$ & $\mathbf{2 3 . 6 5}$ & $\mathbf{2 8 . 8 6}$ & $\mathbf{3 2 . 9 8}$ \\
Food and live animals & 8.85 & 6.41 & 5.11 & 4.69 & 5.59 & 4.92 \\
Beverage and tobacco & 0.79 & 0.69 & 0.45 & 0.41 & 0.51 & 0.55 \\
Crude materials excluding fuels & 6.99 & 4.93 & 2.76 & 3.37 & 4.30 & 4.86 \\
Mineral fuels, etc. & 20.17 & 8.18 & 9.97 & 13.20 & 14.96 & 18.30 \\
Animal, vegetable oil, and fats & 2.25 & 2.51 & 1.43 & 1.98 & 3.50 & 4.34 \\
Manufactured products & $\mathbf{5 9 . 9 8}$ & $\mathbf{7 3 . 7 3}$ & $\mathbf{7 8 . 2 5}$ & $\mathbf{7 4 . 1 9}$ & $\mathbf{6 7 . 3 7}$ & $\mathbf{6 2 . 1 8}$ \\
Chemicals & 3.73 & 4.40 & 5.02 & 7.62 & 7.87 & 9.21 \\
Manufactured goods & 11.28 & 10.33 & 8.24 & 8.24 & 8.61 & 8.59 \\
Machines and transport equipment & 32.33 & 46.58 & 53.71 & 48.06 & 40.54 & 36.10 \\
Miscellaneous manufactured goods & 12.65 & 12.42 & 11.29 & 10.26 & 10.35 & 8.29 \\
Unclassified goods & $\mathbf{0 . 9 7}$ & $\mathbf{3 . 5 6}$ & $\mathbf{2 . 0 2}$ & $\mathbf{2 . 1 6}$ & $\mathbf{3 . 7 7}$ & $\mathbf{4 . 8 4}$ \\
\hline
\end{tabular}

SOURCE: The authors' computation based on the UN Comtrade database.

clined over the years, while the share of chemicals and unclassified goods has increased. However, while exports of chemicals and machines and transport equip-ment have risen and fallen, they continue to account for more than $45 \%$ of total exports. This indicates that ASEAN member countries have moved into the patent- sensitive stage.

\section{Estimated Results}

Table 2 presents the summary of statistics for the data used in our estimation. Most variables, except $\log A_{r e} a_{i}$ and $\log A \mathrm{Are}_{j}$, appear to reflect small differences. Before estimating the GMM model, we conduct the Fisher test for panel unit root using an augmented Dickey-Fuller test. Table 3 presents the results of the test. The null hypothesis of non-stationarity is rejected at the 0.01 level. In other words, all important variables, including Log Export, Log GDP $i t, \log$ GDP $_{j t}$, OPENNESS $_{i t}$, and OPENNESS $_{j t}$ do not have unit roots.

Table 4 reports the results of our one-step GMM estimation. The data fits the gravity model well. The model explains a major part of the variation in bilateral trade. The conventional variables behave much as the model predicts. The Arellano-Bond test for $\operatorname{AR}(2)$ in first differences fails to reject the null hypothesis of no autocorrelation. In other words, the system GMM is efficient in this case. All the estimated coefficients, except $\mathrm{POP}_{\mathrm{it}}$ and Colony $\mathrm{y}_{\mathrm{ij}}$, are statistically significant at the 0.05 significance level.

The coefficient of Lag Export $t_{i t-1}$ is positive and statistically significant at the 0.01 level. This means that the previous year's exports affect the export level for 
the current year. GDP turns out to be an important explanatory variable. The GDPs of both exporting and importing countries register positive and highly significant impacts on bilateral trade. The coefficient of GDP ${ }_{i t}$ indicates that keeping other variables constant, a $1 \%$ increase in the GDP of the exporting (ASEAN member) country increases that country's exports by approximately $0.781 \%$. The coefficient of the importing country's GDP $\left(\mathrm{GDP}_{j t}\right)$ is also positive with an elasticity of 0.397 . It means that a $1 \%$ increase in the GDP of the importing country increases ASEAN's exports by approximately $0.397 \%$.

TABLE 2. SUMMARY OF STATISTICS

\begin{tabular}{|c|c|c|c|c|c|}
\hline Variable & Observation & Mean & Std. Dev. & Minimum & Maximum \\
\hline Log Export ${ }_{i j t}$ & 3,600 & 4.638 & 1.333 & 0.000 & 7.620 \\
\hline $\log _{\text {Export }_{i j t-1}}$ & 3,000 & 4.605 & 1.350 & 0.000 & 7.550 \\
\hline $\log \mathrm{GDP}_{i t}$ & 3,600 & 2.271 & 0.252 & 1.720 & 2.850 \\
\hline $\log _{\operatorname{GDP}_{j t}}$ & 3,600 & 1.897 & 0.856 & 0.050 & 4.160 \\
\hline $\log \mathrm{POP}_{i t}$ & 3,600 & 4.695 & 0.528 & 3.640 & 5.380 \\
\hline $\log \mathrm{POP}_{j t}$ & 3,600 & 4.092 & 0.696 & 2.480 & 6.130 \\
\hline $\log _{\operatorname{DIST}_{i j}}$ & 3,600 & 3.877 & 0.308 & 2.320 & 4.280 \\
\hline Log Area $_{i}$ & 3,600 & 5.225 & 1.101 & 2.840 & 6.280 \\
\hline $\log _{\text {Area }_{j}}$ & 3,600 & 5.244 & 0.894 & 2.500 & 7.230 \\
\hline Openness $i t_{i t}$ & 3,600 & 0.739 & 0.483 & 0.220 & 1.860 \\
\hline Openness $j t_{j t}$ & 3,600 & 0.278 & 0.173 & 0.020 & 1.030 \\
\hline Language $_{i j}$ & 3,600 & 0.073 & 0.261 & 0.000 & 1.000 \\
\hline Colony $_{i j}$ & 3,600 & 0.025 & 0.156 & 0.000 & 1.000 \\
\hline Landlock $_{j}$ & 3,600 & 0.162 & 0.368 & 0.000 & 1.000 \\
\hline $\mathrm{IPR}_{j t}$ & 3,600 & 0.758 & 0.143 & 0.100 & 0.980 \\
\hline $\mathrm{IPR}_{j t} \times \mathrm{LD}_{j t}$ & 3,600 & 0.099 & 0.236 & 0.000 & 0.900 \\
\hline $\mathrm{IPR}_{j t} \times \mathrm{MD}_{j t}$ & 3,600 & 0.334 & 0.360 & 0.000 & 0.920 \\
\hline $\mathrm{IPR}_{j t} \times \mathrm{HD}_{j t}$ & 3,600 & 0.324 & 0.427 & 0.000 & 0.980 \\
\hline
\end{tabular}

TABle 3. PANEl Unit Root Test

\begin{tabular}{lcc}
\hline ADF-Fisher $\chi^{2}$ & Statistic & Probability \\
\hline Log Export $i j t$ & 4340.38 & 0.000 \\
Log GDP $_{i t}$ & 3681.93 & 0.000 \\
Log GDP $_{j t}$ & 2971.70 & 0.000 \\
Openness $i t$ & 1437.03 & 0.000 \\
Openness $j t$ & 3663.56 & 0.000 \\
IPR $_{j t}$ & 3464.12 & 0.000 \\
\hline
\end{tabular}

$\mathrm{H}_{0}$ : All series are non-stationary.

$\mathrm{H}_{1}$ : At least one series is stationary. 
TABLE 4. RESULTS OF THE SYS-GMM DYNAMIC MODEL

\begin{tabular}{|c|c|c|c|}
\hline Explanatory Variables & Coefficients & Standard error & Significance \\
\hline Constant & -3.524 & 0.40 & $* *$ \\
\hline $\log _{\text {Export }_{i j t-1}}$ & 0.304 & 0.07 & $* *$ \\
\hline $\log _{\mathrm{GDP}_{i t}}$ & 0.781 & 0.08 & $* *$ \\
\hline $\log _{G^{\prime}} P_{j t}$ & 0.397 & 0.05 & $* *$ \\
\hline $\log \mathrm{POP}_{i t}$ & 0.088 & 0.06 & - \\
\hline $\log \mathrm{POP}_{j t}$ & 0.475 & 0.06 & $* *$ \\
\hline $\log ^{D_{I S T}} i j$ & -0.185 & 0.03 & $* *$ \\
\hline Log Area $_{i}$ & 0.313 & 0.03 & $* *$ \\
\hline Log Area $_{j}$ & -0.083 & 0.02 & $* *$ \\
\hline Openness $i t$ & 1.136 & 0.10 & $* *$ \\
\hline Openness $j t$ & 0.156 & 0.05 & $* *$ \\
\hline Language $_{i j}$ & 0.211 & 0.04 & $* *$ \\
\hline Colony $_{i j}$ & 0.025 & 0.05 & - \\
\hline Landlock $_{j}$ & -0.387 & 0.04 & $* *$ \\
\hline $\mathrm{IPR}_{j t} \times \mathrm{LD}_{j t}$ & 0.479 & 0.10 & $* *$ \\
\hline $\mathrm{IPR}_{j t} \times \mathrm{MD}_{j t}$ & 0.650 & 0.10 & $* *$ \\
\hline $\mathrm{IPR}_{j t} \times \mathrm{HD}_{j t}$ & 0.946 & 0.12 & $* *$ \\
\hline
\end{tabular}

NOTES: Sargan test of overidentifying restrictions: $\chi^{2}(3)=6.25$ Prob $>\chi^{2}=0.100$.

Arellano-Bond test for AR(1) in first differences: $z=-9.15 \operatorname{Pr}>z=0.000$.

Arellano-Bond test for AR(2) in first differences: $z=-0.03 \operatorname{Pr}>z=0.979$.

${ }^{*}$ Significant at the 0.05 level, ${ }^{* *}$ significant at the 0.01 level.

The coefficients of both population variables, $\mathrm{POP}_{i t}$ and $\mathrm{POP}_{j t}$, are positive, but statistically insignificant for $\mathrm{POP}_{i t}$. This could be because the effects of economies of scale are bigger than the absorption effects. In our estimation, on average, a $1 \%$ increase in the populations of the exporting and importing countries would increase bilateral trade by 0.088 and $0.475 \%$, respectively.

Geographical distance (DIST $i j$ ) between the ASEAN countries and importing countries is found to be negative and highly statistically significant. As predicted by trade theories, a negative value might indicate that ASEAN countries export less to distant partner countries due to higher cost of international transportation, time, and access to relevant market information. On average, for each increase of $1 \%$ in the distance between an ASEAN country and its trading partner, the bilateral trade between them decreases by $0.185 \%$. The coefficients of Area ${ }_{i}$ and Area $_{j}$ are positive and statistically significant. This means that in the case of ASEAN's ex-ports, the economies of scale effect is dominant.

The coefficients on the openness index of both countries are highly statistically significant. The result indicates that ASEAN countries tend to export to countries with some level of openness. As the model estimates, an increase in the level of the openness of the exporting country (ASEAN) would lead to an increase 
in bilateral trade by $1.14 \%$, while an increase in the level of openness of the importing countries would lead to an increase in bilateral trade by $0.16 \%$.

We also find the traditional positive signs on colonial-based relationships, such as Language ${ }_{i j}$ and Colony $i j$, and a negative sign for landlocked countries. We estimate that an ex-common colonizer could raise ASEAN's exports by $2.5 \%$; that two countries speaking the same language could raise ASEAN's exports by $23.5 \%$; and that being a landlocked importing country could reduce ASEAN's exports to that country by $0.32 \%$.

Finally, our primary interest lies in the impact of IPR on ASEAN's exports. Specifically, we focus on the impact of variations in the strength of national IPR for countries grouped by the level of economic development. We find that all the coefficients of the development dummy variables $\left(\mathrm{IPR}_{j t} \times \mathrm{LD}_{j t}, \mathrm{IPR}_{j t} \times \mathrm{MD}_{j t}\right.$, and $\mathrm{IPR}_{j t} \times \mathrm{HD}_{j t}$ ) are positive and statistically significant, exhibiting the market expansion effects on ASEAN's exports to countries of all levels of economic development.

This result is consistent with those of Maskus and Penubarti (1995), Rafiquzzaman (2002), and Smith (1999, 2002). Using an augmented version of the HelpmanKrugman model of monopolistic competition, Maskus and Penubarti (1995) found that market expansion effects dominate market power effects and that national differences in IPR distort international trade flows. Smith (1999) showed that US exports are sensitive to patent rights in importing countries, and the direction of the relationship rests with the threat of imitation. The threat of imitation is viewed as a reflection of an importing country's ability to imitate technologies embodied in the imported goods. More specifically, market power effects are believed to be dominant in the case of exports to countries with weaker imitative abilities, while market expansion effects are prevalent in the case of exports to countries with stronger imitative abilities. Rafiquzzaman (2002) also found similar results, namely that stronger patent rights led to market expansion effects in the case of Canadian exports to countries posing strong imitation threats and market power effects in the case of exports to countries posing weaker imitation threats. These findings were confirmed by Smith (2002), who showed that stronger foreign patent rights stimulate and reduce US drug exports to countries with strong and weak imitative abilities, respectively.

Our study indicates that ASEAN countries tend to respond positively to IPR protection strength in foreign markets. The enforcement of IPR leads to market expansion effects on ASEAN's exports regardless of the level of economic development. This effect is most prevalent in high-income countries, followed by middleincome countries, and finally, low-income countries.

\section{Sectoral Impacts of IPR Protection}

Table 5 presents the empirical results for the GMM model for five commo- 
dity groups including raw material-intensive goods, labor-intensive goods, easily imitable research-oriented goods, difficultly imitable research-oriented goods, and capital-intensive goods. Following Heo and Doanh (2012), our analysis focuses on the response of ASEAN's commodity group exports to the variation in IPR protection in non-ASEAN countries at similar levels of economic development. Overall, the model performs relatively well. The Sargan test of over-identifying restriction suggests that the instruments are valid and that the system GMM estimator is appropriate.

Most of the control variables (GDPs of ASEAN countries and their trading partners, distances between ASEAN countries and their trading partners, and Land$\operatorname{lock}_{j}$ ) exhibit the expected signs and are statistically significant at the 0.01 level. Specifically, the estimated coefficients on the log products of $\mathrm{GDP}_{i t}$ and $\mathrm{GDP}_{j t}$ are positive and highly statistically significant. Since these variables are the proxies for national income, this result strongly supports the hypothesis that market size is the key determinant of trade. We also find the customary negative signs on the distance (DIST $i j$ ) and landlock (Landlock ${ }_{j}$ ) variables and the positive sign on the common language variable (Language $e_{i j}$ ) for all five commodity groups. These results indicate that ASEAN countries export less to distant partner countries due to higher trading costs (including international transportation costs) and access to relevant market information.

Regarding the impact of IPR protection, the estimated coefficients of all interacttion dummy variables (IPR ${ }_{j t} \times \mathrm{LD}_{j t}$, IPR $\mathrm{I}_{j t} \times \mathrm{MD}_{j t}$, and $\left.\mathrm{IPR}_{j t} \times \mathrm{HD}_{j t}\right)$ are positive and statistically significant at the 0.01 level. The estimated coefficient of $\operatorname{IPR}_{j t} \times \mathrm{HD}$ for ASEAN's total exports is 0.946, while the coefficients of $\mathrm{IPR}_{j t} \times \mathrm{HD}$ for ASEAN's exports of raw material-intensive goods, labor-intensive goods, easily imitable research-oriented goods, difficultly imitable research-oriented goods, and capitalintensive goods are 1.231, 1.291, 1.447, 1.149, and 1.648, respectively. Similarly, while the estimated coefficient of $\mathrm{IPR}_{j t} \times \mathrm{MD}$ for ASEAN's total exports is 0.650 , the coefficients of IPR ${ }_{j t} \times \mathrm{MD}$ for ASEAN's exports of raw material-intensive goods, labor-intensive goods, easily imitable research-oriented goods, difficultly imitable research-oriented goods, and capital-intensive goods are 1.075, 1.133, 1.086, 1.162, and 0.912 , respectively. For ASEAN's exports to less economically developed countries, the result is similar.

For low-income countries, the effects of IPR protection appear to be stronger for the labor-intensive and difficultly imitable research-oriented goods commodity groups, and weaker for the raw material-intensive and capital-intensive goods commodity groups. For medium-income countries, the result is almost similar. The effects of IPR protection appear to be stronger for labor-intensive and difficultly imitable research-oriented goods, and weaker for raw material and capital-intensive goods. For high-income countries, the result is significantly different. The effects of IPR protection appear to be stronger for the capital-intensive and easily 
TABLE 5. SECTORAL IMPACTS OF IPR PROTECTION

\begin{tabular}{|c|c|c|c|c|c|c|c|c|c|c|}
\hline \multirow{2}{*}{$\begin{array}{c}\text { Explanatory } \\
\text { Variables }\end{array}$} & \multicolumn{2}{|c|}{$\begin{array}{c}\text { Raw } \\
\text { Material }\end{array}$} & \multicolumn{2}{|c|}{$\begin{array}{l}\text { Labor- } \\
\text { Intensive }\end{array}$} & \multicolumn{2}{|c|}{$\begin{array}{c}\text { Easily } \\
\text { Imitable }\end{array}$} & \multicolumn{2}{|c|}{$\begin{array}{l}\text { Difficultly } \\
\text { Imitable }\end{array}$} & \multicolumn{2}{|c|}{$\begin{array}{l}\text { Capital- } \\
\text { intensive }\end{array}$} \\
\hline & $\begin{array}{l}\text { Coeffi } \\
\text { cient }\end{array}$ & $\begin{array}{l}\text { Std. } \\
\text { Err. }\end{array}$ & $\begin{array}{c}\text { Coeffi } \\
\text { cient }\end{array}$ & $\begin{array}{l}\text { Std. } \\
\text { Err. }\end{array}$ & $\begin{array}{c}\text { Coeffi } \\
\text { cient }\end{array}$ & $\begin{array}{l}\text { Std. } \\
\text { Err. }\end{array}$ & $\begin{array}{l}\text { Coeffi } \\
\text { cient }\end{array}$ & $\begin{array}{l}\text { Std. } \\
\text { Err. }\end{array}$ & $\begin{array}{c}\text { Coeffi } \\
\text { cient }\end{array}$ & $\begin{array}{l}\text { Std. } \\
\text { Err. }\end{array}$ \\
\hline Constant & 2.398 & 2.40 & $5.855^{* *}$ & 2.01 & $1.755^{* *}$ & 0.66 & $2.345^{* *}$ & 0.64 & $-4.526^{* *}$ & 1.62 \\
\hline Log Export $_{i j t-1}$ & 0.139 & 0.20 & 0.015 & 0.11 & $0.186^{* *}$ & 0.05 & $0.353^{* *}$ & 0.11 & 0.074 & 0.09 \\
\hline $\log \operatorname{GDP}_{i t}$ & $0.764^{* *}$ & 0.21 & $0.328^{* *}$ & 0.11 & $1.301^{* *}$ & 0.08 & $1.664^{* *}$ & 0.13 & $0.962^{* *}$ & 0.22 \\
\hline $\log \operatorname{GDP}_{j t}$ & $0.513^{* *}$ & 0.12 & $0.742^{* *}$ & 0.11 & $0.339^{* *}$ & 0.14 & $0.649^{* *}$ & 0.08 & $0.661^{*}$ & 0.19 \\
\hline $\log \mathrm{POP}_{i t}$ & -0.495 & 0.50 & $-1.230^{* *}$ & 0.44 & $-0.785^{* *}$ & 0.08 & $-1.197^{* *}$ & 0.10 & 0.100 & 0.14 \\
\hline $\log \mathrm{POP}_{j t}$ & $0.610^{* *}$ & 0.16 & $0.516^{* *}$ & 0.13 & $0.618^{* *}$ & 0.08 & $0.365^{* *}$ & 0.09 & $1.115^{* *}$ & 0.27 \\
\hline $\log _{\operatorname{DIST}_{i j}}$ & $-0.652^{* *}$ & 0.07 & $-0.183^{* *}$ & 0.04 & $-0.428^{* *}$ & 0.14 & $-0.209^{* *}$ & 0.05 & $-0.227^{* *}$ & 0.07 \\
\hline Log $\operatorname{Area}_{i}$ & $0.542^{* *}$ & 0.06 & $0.590^{* *}$ & 0.06 & $0.356^{* *}$ & 0.03 & $0.423^{* *}$ & 0.05 & $0.522^{* *}$ & 0.08 \\
\hline Log Area $_{j}$ & $-0.121^{* *}$ & 0.03 & $-0.175^{* *}$ & 0.02 & -0.003 & 0.05 & $-0.172^{* *}$ & 0.02 & $-0.282^{* *}$ & 0.10 \\
\hline Openness $_{i t}$ & 0.657 & 0.45 & -0.054 & 0.60 & $0.684^{* *}$ & 0.09 & $0.447^{* *}$ & 0.16 & $1.458^{* *}$ & 0.29 \\
\hline Openness $_{j t}$ & -0.053 & 0.09 & 0.519 & 1.27 & $0.665^{* *}$ & 0.10 & $0.365^{* *}$ & 0.08 & -0.783 & 0.44 \\
\hline Language $_{i j}$ & $0.203^{* *}$ & 0.06 & 0.071 & 0.04 & 0.122 & 0.07 & $0.116^{*}$ & 0.06 & $0.533^{* *}$ & 0.20 \\
\hline Colony $_{i j}$ & $0.206^{* *}$ & 0.08 & 0.192 & 0.15 & 0.093 & 0.07 & -0.034 & 0.08 & -8.750 & 5.72 \\
\hline Landlock $_{j}$ & $-0.827^{* *}$ & 0.12 & $-0.541^{* *}$ & 0.07 & $-1.986^{* *}$ & 0.71 & $-0.325^{* *}$ & 0.07 & $-0.353^{* *}$ & 0.06 \\
\hline $\mathrm{IPR}_{j t} \times \mathrm{LD}_{j t}$ & $0.790^{* *}$ & 0.25 & $1.142^{* *}$ & 0.33 & $0.905^{* *}$ & 0.12 & $1.028^{* *}$ & 0.16 & $0.548^{* *}$ & 0.12 \\
\hline $\mathrm{IPR}_{j t} \times \mathrm{MD}_{j t}$ & $1.075^{* *}$ & 0.27 & $1.133^{* *}$ & 0.25 & $1.086^{* *}$ & 0.10 & $1.162^{* *}$ & 0.15 & $0.912^{* *}$ & 0.12 \\
\hline $\mathrm{IPR}_{j t} \times \mathrm{HD}_{j t}$ & $1.231^{* *}$ & 0.36 & $1.291^{* *}$ & 0.22 & $1.447^{* *}$ & 0.15 & $1.149^{* *}$ & 0.19 & $1.648^{* *}$ & 0.40 \\
\hline Sargan test & & 5.500 & & 3.83 & & 11.800 & & 7.150 & & 5.130 \\
\hline $\operatorname{Pr}>\chi^{2}$ & & 0.540 & & 0.275 & & 0.067 & & 0.067 & & 0.077 \\
\hline
\end{tabular}

SOURCE: Regression result.

NOTES: Std. Err. means standard error, ${ }^{*}$ Significant at the 0.05 level, ${ }^{* *}$ significant at the 0.01 level.

imitable research-oriented goods commodity groups, and weaker for the raw material-intensive and difficultly imitable research-oriented goods commodity groups.

Our results support the theoretical prediction that IPR protection has dominant market expansion effects and are consistent with the previous evidence provided by Doanh and Heo (2007), Jung (2007), and Oh and Won (2005). However, our results contradict those of Fink and Primo-Braga (2005) and Kang and Park (2006). While Fink and Primo-Braga (2005) confirmed market expansion effects for aggregate nonfuel trade, they could not find a significant link between IPR and high-technology trade. Kang and Park (2006) analyzed the impacts of the strength of foreign IPR on Korean exports by trading partners and industries. They found that market power effects were dominant in exports to developing countries for low-tech industries, while market expansion effects dominated in high-tech Industry exports to developed countries. Thus, our comparative review of previous studies and the results of our model confirm that the linkage between IPR protection enforcement and trade flows remains case-specific. 


\section{CONCLUSION}

This paper investigated the impact of IPR protection in foreign countries on ASEAN's exports using a GMM estimator. Our empirical results are robust. The major findings are summarized as follows.

First, since the coefficient on the IPR index is positive and statistically significant for ASEAN's total exports, we conclude that stronger IPR protection in foreign countries (the rest of the world) induces ASEAN's exports. Therefore, in the case of ASEAN's total exports, market expansion effects dominate market power effects.

Second, stronger IPR protection induces ASEAN's exports to all foreign countries regardless of their level of economic development, which again exhibits market expansion effects on ASEAN's exports to countries of all development groups. The impacts of IPR protection are strongest in high-income countries, followed by medium-income, and finally, low-income countries. This means that ASEAN member countries tend to export more to high- and medium-income countries than to low-income countries when IPR protection in these countries is strengthened.

Third, at the sectoral level, greater IPR protection in foreign countries has positive effects on ASEAN's exports to these countries for all product categories, regardless of their level of economic development. Compared with the total exports of ASEAN countries, the impact is relatively stronger at the sectoral level.

Fourth, for low- and medium-income countries, the effects of IPR protection appear to be stronger in the labor-intensive and difficultly imitable research-oriented goods commodity groups, and weaker in the raw material-intensive and capitalintensive goods commodity groups. For high-income countries, the effects of IPR protection appear to be stronger in the capital-intensive and easily imitable research-oriented goods commodity groups, and weaker in the raw material-intensive and difficultly imitable research-oriented goods commodity groups. Overall, the effect of IPR protection is found to be the strongest in ASEAN's capital-intensive exports to highly developed countries and the weakest in ASEAN's capital-intensive exports to less developed countries.

Finally, the signs of the coefficients of the traditional variables suggest that ASEAN tends to export more to countries with higher GDP, higher degrees of openness to trade, countries speaking the same language, and countries having colonial relationships with ASEAN member countries. In contrast, ASEAN tends to export less to landlocked countries and countries distant from the region.

The implication is that ASEAN's exports would increase further if appropriate measures are taken to strengthen IPR protection in foreign countries. However, these measures must be accompanied by efforts to facilitate trade, such as improving social infrastructure and accelerating domestic reforms to reduce trade costs 
for both ASEAN member countries and its trading partners.

\section{REFERENCES}

Al-Mawali, N. 2005. Bilateral Intra-Industry Trade Flows and Intellectual Property Rights Protection: First Empirical Evidence, Applied Economic Letters 12: 823-828.

Blundell, R. and S. Bond. 1998. Initial Conditions and Moment Restrictions in Dynamic Panel Data Models, Journal of Econometrics 87(1): 115-143.

Doanh, N. K. and Y. Heo. 2007. Impacts of Intellectual Property Right Protection on Trade Flows in ASEAN Countries, Journal of International and Area Studies 14(1): 1-15.

Ethier, W. J. And J. R. Markusen, 1996. Multinational Firms, Technology Diffusion and Trade, Journal of International Economics 41: 1-28.

Endoh, M. 1999. Trade Creation and Trade Diversion in the EEC, the LAFTA and the CMEA: 1960-1994, Applied Economics 31: 207-216.

Endoh, M. 2000. The Transition of Postwar Asia-Pacific Trade Relations, Journal of Asian Economics 10: 571-589.

Ferrantino, M. J. 1993. The Effects of Intellectual Property Rights on International Trade and Investment, Weltwirtschaftliches Archive 129: 300-331.

Fink, C. and C. A. Primo-Braga, 2005. How Stronger Protection of Intellectual Property Rights Affects International Trade Flows, in C. Fink and K. E. Maskus ed., Intellectual Property and Development: Lessons from Recent Economic Research. Washington, DC: The International Bank for Reconstruction and Development/The World Bank: 19-40.

Frankel, J. A. 1993. Is Japan Creating a Yen Block in East Asia and the Pacific? In J. Frankel and M. Kahler (ed.), Regionalism and Rivalry: Japan and the United States in Pacific Asia. Chicago: University of Chicago Press.

Heo, Y. and N. K. Doanh. 2012. Intellectual Property Rights, Imitative Ability and Export Performance: The Korean Experience, International Studies Review 13(1): 19-41.

Jafari, Y., M. A. Ismail, and M. S. Kouhestani. 2011. Determinants of Trade Flows among D8 Countries: Evidence from the Gravity Model, Journal of Economic Cooperation and Development 32(3): 21-38.

Jung, M.-H. 2007. The Effects of Interaction of the Foreign Intellectual Property Rights and Imitation Ability on the Export Patterns of IT Industrial Sectors in Korea, The Journal of Korea Research Society for Customs 8(1): 231-258.

Kang, H.-J. and K-Y. Park. 2006. The Effects of Foreign Intellectual Property Rights (IPRs) on the Export Volume of Korea, Korea Trade Review 31(4): 531.

Lee, J.-E. and E. Mansfield, 1996. Intellectual Property Right Protection and U.S. 
Foreign Direct Investment, Review of Economics and Statistics 78(2): 181186.

Martinez-Zarzoso, I. 2003. Gravity Model: An Application to Trade between Regional Blocs, Atlantic Economic Journal 31(2): 174-187.

Martinez-Zarzoso, I. and F. Nowak-Lehmann. 2003. Augmented Gravity Model: An Empirical Application to Mercosur-European Union Trade Flows, Journal of Applied Economics 6(2): 291-316.

Maskus, K. E. 1998. The International Regulation of Intellectual Property, Weltwirtschaftliches Archiv 134(2): 186-208.

Maskus, K. E. 2000. Intellectual Property Rights in the Global Economy, Washington, DC: Institute for International Economics.

Maskus, K. E. and M. Penubarti. 1995. How Trade-related Are Intellectual Property Rights?. Journal of International Economics 39: 227-248.

Oguledo, V. I. and C. R. Macphee. 1994. Gravity Models: A Reformulation and an Application to Discriminatory Trade Arrangements, Applied Economics 26, 107-120.

Oh, K.-Y. and J. I. Won, 2005. The Effects of Patent Rights on International Trade: Evidence of Korea, Journal of International Trade and Industry Studies 10(1): 19-42.

Peridy, N. 2005. The Trade Effects of the Euro-Mediterranean Partnership: What Are the Lessons for ASEAN Countries, Journal of Asian Economics 16, 125 139.

Raballand, G. 2003. Determinants of the Negative Impact of Being Landlocked on Trade: An Empirical Investigation Through the Central Asian Case, Comparative Economic Studies 45: 520-536.

Rafiquzzaman, M. 2002. The Impact of Patent Rights on International Trade: Evidence from Canada, The Canadian Journal of Economics 35(2): 307-330.

Seyoum, B. 1996. The impact of Intellectual Property Rights on Foreign Direct Investment, Columbia Journal of World Business 31(1): 50-59.

Smith, P. J. 1999. Are Weak Patent Rights a Barrier to U.S. Exports? Journal of International Economics 48: 151-177.

Smith, P. J. 2001. How Do Foreign Patent Right Affect U.S. Exports, Affiliate Sales, and Licenses? Journal of International Economics 55: 411-439.

Smith, P. J. 2002. Patent Rights and Trade: Analysis of Biological Products, Medicinals and Botanicals, and Pharmaceuticals, American Journal of Agricultural Economics 84(2): 495-512.

Sohn, Chan-Hyun. 2005. Does the Gravity Model Explain South Korea's Trade Flows?. The Japanese Economic Review 56(4), 417-430.

Wen-Hsien, L. and L. Ya-Chi. 2005. Foreign Patent Right and High-Tech Export: Evidence from Taiwan, Applied Economics 37(13): 1543-1555. 